Article received 05.12.2018 p.

Article accepted 27.12.2018 p.

$@ \bowtie$ Correspondence author удК 628.381.1

I. Yu. Popadiuk popaduk_i@ukr.net

В. М. Жук, О. В. Вербовський, І. Ю. Попадюк, І. І. Матлай

Національний університет "Львівська політехніка", м. Львів, Україна

\title{
ОСНОВНІ ТЕХНОЛОГІЧНІ ПАРАМЕТРИ РЕАЛІЗАЦІЇ АЕРОБНОГО БІОКОМПОСТУВАННЯ ОСАДІВ СТІЧНИХ ВОД
}

Перспективним шляхом утилізації осадів стічних вод на каналізаційних очисних спорудах є їх аеробне біокомпостування $з$ отриманням органо-мінеральної суміші. Представлено узагальнену математичну модель, що враховує геометричні розміри компостних буртів і товщину зони охолодження та дає змогу прогнозувати та оптимізувати основні технологічні параметри реалізації процесу аеробного компостування осадів. Показано, що без урахування технічних обмежень максимально досяжний відносний ефективний об'єм зростає зі збільшенням висоти бурту $H$, коефіцієнта закладання його відкосів $m$ та відносної довжини бурту $L / H$. Для довгих буртів із $L / H \geq 20$ впливом торцевих зон на значення відносного ефективного об'єму можна нехтувати. За сталого значення площі поперечного перерізу довгих буртів максимальні значення відносного ефективного об'єму відповідають коефіцієнту закладання відкосів $m=1$. Розроблена модель дає змогу розв'язати оптимізаційну задачу для фіксованого об'єму компостного бурту за наявності технічних обмежень щодо максимального значення висоти $H$. У практично вагомому діапазоні значень вихідних параметрів $\left(W_{t o t}=50-500 \mathrm{~m}^{3} ; H_{\max }=2 \mathrm{м} ; a=0,3-0,5 \mathrm{м}\right)$ максимальний відносний ефективний об'єм відповідає буртам невеликої довжини $L / H<20$ зі значеннями коефіцієнта закладання відкосів $m>1$. Це пояснено тим, що такі бурти мають мінімальну площу поверхні розділу з повітрям, що мінімізує об'єм зон охолодження за сталого об'єму і висоти бурту.

Ключові слова: аеробне біокомпостування; осади стічних вод; активна зона; зона охолодження; відносний ефективний об'єм; оптимізаційна задача.

Вступ. Збільшення кількості мешканців, зростаюча урбанізація та підвищення рівня благоустрою населених пунктів призводить до постійного зростання продуктивності каналізаційних очисних споруд (КОС), а отже, до збільшення обсягів осадів стічних вод (OCB). Для дотримання вимог концепції сталого розвитку ОСВ повинні бути якомога повніше перероблені та утилізовані, не створюючи при цьому негативного впливу на довкілля. Найпоширенішими методами оброблення ОСВ є їх гравітаційне ущільнення, механічне зневоднення, анаеробне зброджування, підсушування та стабілізація на мулових майданчиках, аеробне компостування, термічне сушіння та спалювання (Volskyi et al., 2017; Wong et al., 2016). Загальний об'єм осадів, що утворюються внаслідок очищення міських стічних вод на КОС, становить 0,5-1,0 \% від кількості очищених стічних вод за вологості осадів відповідно 97-98 \% (Horodnii, 2013). Отож, за рік утворюється в середньому близько $1 \mathrm{~m}^{3}$ осадів вологістю $97 \% 3$ розрахунку на одного еквівалентного мешканця. Виходячи зі сумарної фактичної продуктивності КОС, в Україні щороку утворюється близько 40-50 млн м ${ }^{3}$ ОСВ вологістю $97 \%$ або $1,2-1,5$ млн т осадів у перерахунку на суху речовину.
Основним методом зневоднення осадів на українських КОС досі залишається їх розміщення на мулових майданчиках (Zhuk et al., 2015). Загальна розрахункова потреба в мулових майданчиках для розміщення осадів на українських КОС становить 2000 га/рік, і за відсутності повної утилізації осадів виникає необхідність у виділенні під мулові майданчики щоразу нових земельних ділянок.

Великі об'єми утворюваних і накопичуваних протягом десятиліть ОСВ на українських КОС становлять серйозну загрозу для довкілля. Починаючи з 2016 р., в країнах Євросоюзу заборонено складування ОСВ, тобто мулові майданчики вже не можна використовувати для зневоднення ОСВ. Основними методами остаточного оброблення осадів на КОС у країнах Центральної та Західної Свропи сьогодні стали термічне сушіння та спалювання осадів (Bień \& Bień, 2015). Водночас, методи сушіння та спалювання осадів характеризуються як високою капітальною вартістю, так і особливо великими експлуатаційними видатками.

Перспективною альтернативою $є$ утилізація ОСВ за методом аеробного біокомпостування з отриманням органо-мінеральної суміші, що, залежно від іiі складу,

\section{Інформація про авторів:}

Жук Володимир Михайлович, канд. техн. наук, доцент, кафедра гідравліки та сантехніки. Email: zhuk_vm@ukr.net; https://orcid.org/0000-0002-2275-0799

Вербовський Орест Володимирович, канд. техн. наук, доцент, кафедра гідравліки та сантехніки. Email: owerbow@ukr.net Попадюк Ігор Юрійович, канд. техн. наук, доцент, кафедра гідравліки та сантехніки. Email: popaduk_i@ukr.net

Матлай Іван Іванович, канд. техн. наук, ст. викладач, кафедра гідравліки та сантехніки. Email: i.matlay@gmail.com

Цитування за ДСтУ: Жук В. М., Вербовський О. В., Попадюк І. Ю., Матлай І. І. Основні технологічні параметри реалізації аеробного біокомпостування осадів стічних вод. Науковий вісник НЛтУ України. 2018, т. 28, № 11. С. $91-95$.

Citation APA: Zhuk, V. M., Verbovskiy, O. V., Popadiuk, I. Yu., \& Matlai, I. I. (2018). The main technological parameters of the implementation of aerobic biocomposting of sewage sludge. Scientific Bulletin of UNFU, 28(11), 91-95.

https://doi.org/10.15421/40281117 
можна використати для вирішення багатьох проблем агрокомплексу, рекультивації територій сміттєзвалищ i техногенно порушених земель (Barberio et al., 2013; Białobrzewski et al., 2015). Великого поширення в Україні та за кордоном набуло біокомпостування сільськогосподарських органічних відходів тваринного походження (Pavlenko et al., 2011). Проте реалізація процесу біокомпостування ОСВ $є$ менш поширеною внаслідок як меншої енергетичної цінності ОСВ, так і щодо реалізації кінцевого продукту з огляду на можливий підвищений вміст у ОСВ різних токсичних забруднень.

Компостування ОСВ часто використовують у багатьох країнах Європи, зокрема в Угорщині. За цією технологію обробляють близько 78 \% осадів: у Чехії39 \%, у Німеччині - $12 \%$, у Польщі - $9 \%$ (Świerczek et al., 2018).

Метою роботи є аналіз наявного практичного досвіду реалізації процесу аеробного біокомпостування осадів стічних вод, а також розроблення узагальнених математичних моделей процесів аеробного біокомпостування для можливості оптимізації основних технологічних параметрів його реалізації, зокрема досягнення максимально можливих значень відносного ефективного об'єму.

Об'єктом дослідження є математичне моделювання процесів аеробного біокомпостування осадів стічних вод. У роботі застосовано теоретичний метод математичного моделювання, 3 допомогою якого на підставі узагальнення емпіричних даних щодо умов реалізації процесу аеробного біокомпостування ОСВ сформульовано та розв'язано в загальному вигляді оптимізаційні задачі стосовно основних технологічних параметрів біокомпостування, а саме щодо геометричних характеристик компостних буртів.

Результати дослідження. Основним технологічним параметром процесу біокомпостування є геометричні розміри буртів із компостною сумішшю (Horodnii, 2013; Holub et al., 2016). Оскільки температура в активній зоні під час процесу компостування відносно стабільна і становить $T_{a c t}=70-75^{\circ} \mathrm{C}$, товщина зони охолодження залежить здебільшого від температури зовнішнього середовища.

Нижче розглянуто узагальнену математичну модель, що дає змогу визначати відносний ефективний об'єм $W^{\prime}$ як частку ефективного об'єму $W_{e f}$ активної зони з нормативними температурами до загального об'єму компостного бурту $W_{t o t}$.

Загальний об'єм прямокутного в плані компостного бурту трикутного поперечного перерізу (рис. 1):

$$
W_{t o t}=m H^{2} L+\frac{2}{3} m^{2} H^{3},
$$

де: $m$ - коефіцієнт закладання відкосів компостного бурту; $H$ - висота бурту, м; $L$ - довжина основної частини бурту (без торцевих зон), м.

Активна зона бурту складається $з$ двох частин: середньої призматичної частини та двох торцевих частин пірамідальної форми. Припущено, що товщина зони охолодження у всіх частинах бурту однакова і становить $a$ від поверхні розділу з повітрям (див. рис. 1). Основу, на якій формують компостний бурт, приймають такою, що має низький коефіцієнт теплопередачі, тому товщину зони охолодження в нижній частині бурту в цій моделі не враховано.

Ефективний об'єм середньої частини бурту:

$$
W_{e f .1}=m(H-b)^{2} L,
$$

ефективний об'єм двох торцевих частин:

$$
W_{\text {ef } .2}=\frac{2}{3}(m H-c)^{2}(H-b),
$$

де $b, c$ - висота та ширина зон охолодження відповідно (див. рис. 1).

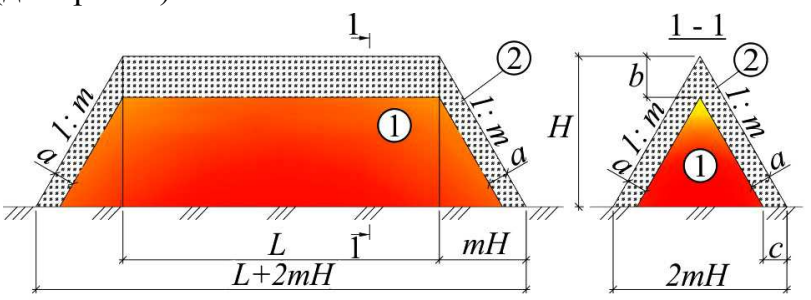

Рис. 1. Схема до визначення відносного об'єму активної зони компостного бурту: 1) активна зона бурту; 2) зона охолодження (захисний шар)

Висота зони охолодження $b$ у верхній частині бурту:

$$
b=\frac{a}{m} \sqrt{1+m^{2}},
$$

а ширина зон охолодження у торцевих частинах:

$$
c=a \sqrt{1+m^{2}} \text {. }
$$

Отже, загальний об'єм активної зони бурту:

$$
W_{e f}=m(H-b)^{2} L+\frac{2}{3}(m H-c)^{2}(H-b) .
$$

Відносний об'єм активної зони компостного бурту (відносний ефективний об'єм):

$$
W^{\prime}=W_{\text {ef }} / W_{\text {tot }} \text {. }
$$

Графічні залежності відносного ефективного об'єму $W^{\prime}$ від висоти бурту для найпростішого випадку дуже довгих буртів $(H / L \rightarrow 0)$ з коефіцієнтом закладання бічних відкосів $m=1$ наведено на рис. 2.

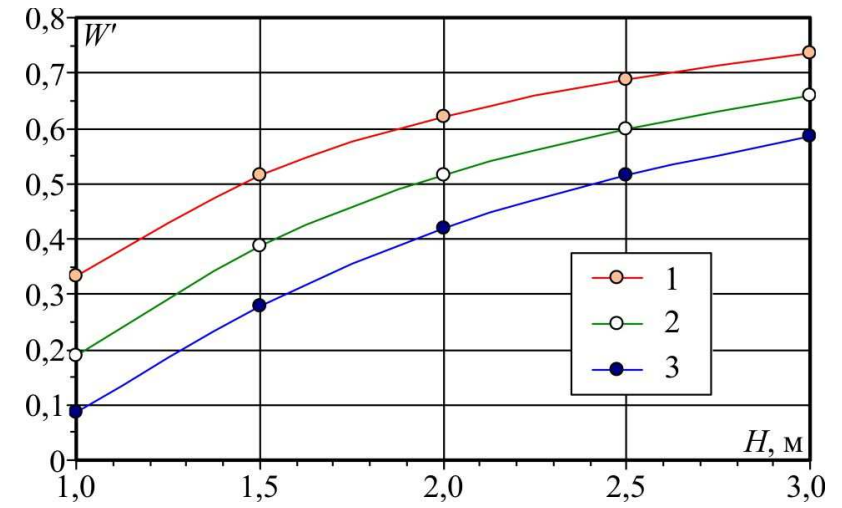

Рис. 2. Вплив висоти бурту трикутного перерізу на відносний об'єм активної зони аеробного компостування ОСВ залежно від товщини зони охолодження: $1-a=0,3 \mathrm{~m} ; 2-a=0,4$ м; $3-a=$ $0,5 \mathrm{м}(m=1, H / L=0)$

Достатньо ефективним є компостування, для якого принаймні 50 \% об'єму компостної суміші знаходиться в активній зоні. Отже, у першому наближенні, для довгих буртів із коефіцієнтом закладання відкосів $m=1$ за значення товщини зони охолодження $a=0,3$ м мінімальною ефективною висотою буртів $є h_{\min .0,3} \geq 1,45 \mathrm{~m}$, тоді як для $a=0,4 \mathrm{M}-h_{\min .0,4} \geq 1,9 \mathrm{M}$, а для $a=0,5 \mathrm{м}-$ $h_{\min .0,5} \geq 2,4 \mathrm{м}$.

Досліджено також вплив висоти трикутного у плані бурту на величину відносного ефективного об'єму $W^{\prime}$ за різних співвідношень геометричних параметрів бурту $(L / H)$. Порівняння залежностей на рис. 2 і 3 показує, що для буртів зі співвідношенням $L / H \geq 20$ об'єм торцевих 
зон практично не впливає на величину відносного ефективного об'єму $W^{\prime}$.

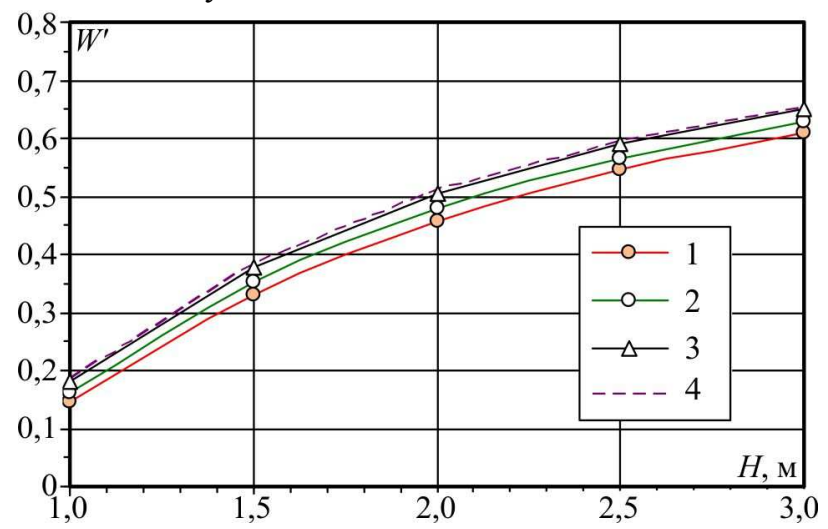

Рис. 3. Вплив висоти бурту трикутного перерізу на відносний об'єм активної зони аеробного компостування ОСВ залежно від довжини бурту: $1-L / H=1 ; 2-L / H=2 ; 3-L / H=5 ; 4-L / H=$ $20(m=1, a=0,4 \mathrm{M})$

Зміна значення коефіцієнтів закладання бічних відкосів $m$ також впливає на величину відносного ефективного об'єму $W^{\prime}$. На рис. 4 наведено графічні залежності відносного ефективного об'єму $W^{\prime}$ від висоти бурту за різних значень $m$ за фіксованих значень товщини зони охолодження $a=0,4$ м для достатньо довгих буртів із відносною довжиною $L / H=20$.

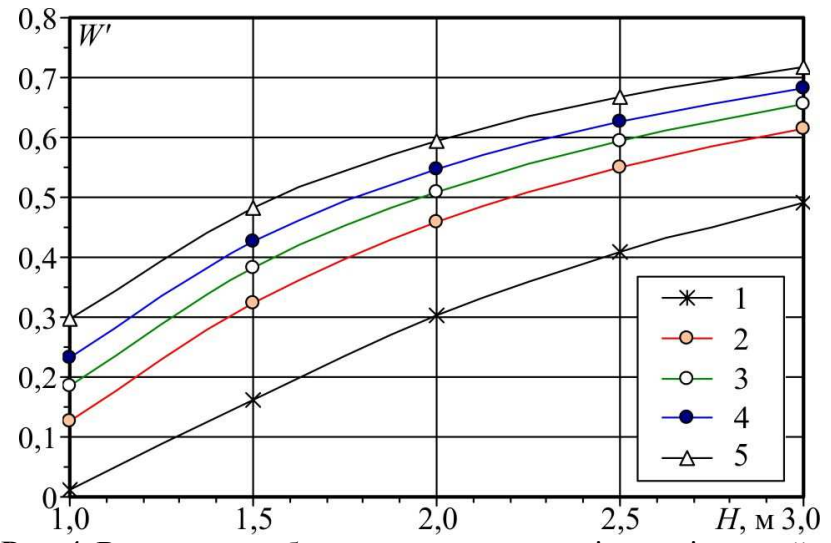

Рис. 4. Вплив висоти бурту трикутного перерізу на відносний об'єм активної зони аеробного компостування ОСВ залежно від значення коефіцієнтів закладання бічних відкосів $m: 1-m=0,5$; $2-m=0,8 ; 3-m=1 ; 4-m=1,25 ; 5-m=2(a=0,4$ м; $L / H=20)$

Визначимо аналітично оптимальне значення коефіцієнта закладання відкосів $m$ довгих буртів $(L / H \geq 20)$ за заданого значення площі поперечного перерізу $\omega_{t o t}$. Оскільки для довгих буртів впливом торцевих зон можна знехтувати, відносний ефективний об'єм:

$$
W^{\prime}=\frac{\omega_{a c t}}{\omega_{t o t}}=\frac{m(H-b)^{2}}{m H^{2}}=\left(1-\frac{a}{H} \frac{\sqrt{1+m^{2}}}{m}\right)^{2},
$$

де $\omega_{e f}, \omega_{t o t}-$ площа перерізу відповідно активної зони та всього бурту.

Оскільки висота $H$ за такої постановки задачі - величина змінна, то виразимо іiі через $\omega_{t o t}$ та $m$, матимемо $H=\sqrt{\omega_{t o t} / m}$. Тоді вираз (8) отримуємо:

$$
W^{\prime}=\left(1-\frac{a}{\sqrt{\omega_{t o t}}} \frac{\sqrt{1+m^{2}}}{\sqrt{m}}\right)^{2} .
$$

Диференціюючи вираз (9), отримуємо, що похідна $d W^{1} d m$ дорівнює нулю при значенні $m=1$, причому функція $W^{\prime}=W^{\prime}(m)$ у точці $m=1$ має максимум.
Однак аналогічний результат можна отримати 3 фізичних міркувань, якщо розглянути функцію довжини периметра охолодження поперечного перерізу бурту, тобто тієї частини периметра, яка має поверхню розподілу з повітрям:

$$
\chi=2 \sqrt{1+m^{2}} H=2 \sqrt{1+m^{2}} \sqrt{\frac{\omega_{t o t}}{m}} .
$$

Функція (10) також має максимум при $m=1$.

Отже, за сталого значення площі поперечного перерізу довгих буртів $(L / H \geq 20)$ максимальні значення відносного ефективного об'єму відповідають коефіцієнту закладання відкосів $m=1$ (рис. 5).

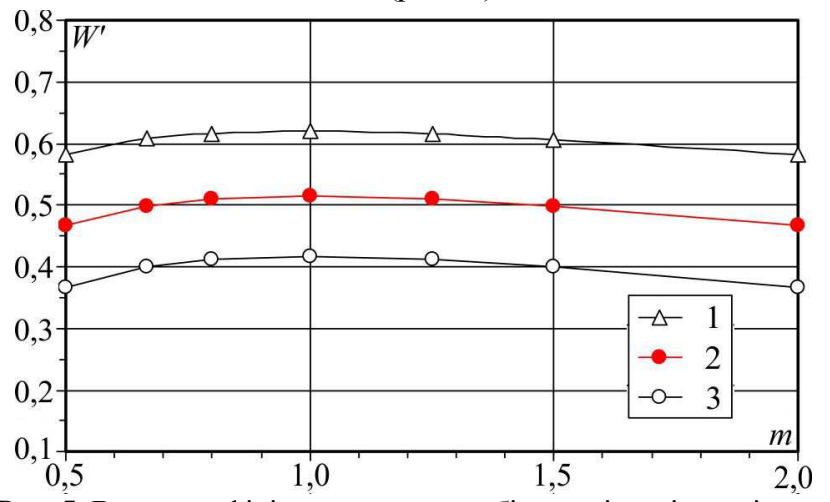

Рис. 5. Вплив коефіцієнта закладання бічних відкосів на відносний об'єм активної зони аеробного компостування ОСВ залежно від товщини зони охолодження: $1-a=0,3 \mathrm{~m} ; 2-a=0,4$ м; $3-a=0,5 \mathrm{~m}\left(\omega_{\mathrm{tot}}=4 \mathrm{~m}^{2} ; H-\operatorname{var} ; L / H \geq 20\right)$

Розглянемо оптимізаційну задачу визначення оптимальних розмірів компостного бурту в найбільш загальній постановці з урахуванням об'ємів торцевих зон, а також урахуванням технічних обмежень реалізації процесу. До числа таких обмежень належить зокрема висота бурту $H$, максимальне значення якої лімітується вибором конкретного технічного засобу для перевертання компосту (зі збільшенням значення $H$ різко зростає вартість спеціалізованої техніки, істотно впливаючи на рентабельність компостування загалом).

Використовуючи рівняння (1) та (4)-(6), отримуємо загальний вираз для відносного ефективного об'єму довільного прямокутного в плані компостного бурту трикутного поперечного перерізу:

$$
W^{\prime}=\frac{m\left(H-\frac{a}{m} \sqrt{1+m^{2}}\right)^{2} L+\frac{2}{3}\left(m H-a \sqrt{1+m^{2}}\right)^{2} \Delta H}{m H^{2} L+2 / 3 m^{2} H^{3}},
$$

де $\Delta H=H-\frac{a}{m} \sqrt{1+m^{2}}$.

Функцію (11) проаналізовано чисельно на наявність максимумів для заданих значень $W_{t o t}, H=H_{\max }$, а також товщини зони охолодження $a$. За такої умови довжина призматичної частини бурту $L \epsilon$ функцією $m$ :

$$
L=\frac{W_{t o t}}{m H^{2}}-\frac{2}{3} m H .
$$

Розглянуто практично вагомий для більшості малих та середніх КОС діапазон значень вихідних параметрів: $W_{t o t}=50-500 \mathrm{~m}^{3} ; H_{\max }=2 \mathrm{м} ; a=0,3-0,5$ м. Оптимальні розміри компостних буртів, що відповідають максимальним значенням відносного ефективного об'єму, наведено в таблиці.

Отримано, що максимальний відносний ефективний об'єм компостного бурту за фіксованих значень $W_{\text {tot }}$ і $H$ $=2$ м відповідає буртам невеликої довжини $L / H<20$ зі 
значеннями коефіцієнта закладання відкосів $m>1$. Оптимальна ширина буртів при $W_{t o t}>100 \mathrm{~m}^{3} \epsilon$ навіть дещо завеликою з погляду практичної реалізації процесу. Однак чим більшим $є$ значення коефіцієнта $m$, тим стійкішим буде бурт, складений з компостної суміші з малим значенням кута внутрішнього тертя. 3 фізичного погляду, результат із максимальним відносним ефективним об'ємом недовгих $(L / H \geq 20)$ буртів із пологими відкосами $(m>1)$ можна пояснити тим, що такі бурти мають мінімальну площу поверхні розділу з повітрям, що мінімізує об'єм зон охолодження за сталого об'єму і висоти бурту.

Таблиця. Оптимальні розміри компостних буртів, що відповідають умові $W^{\prime}=W_{\max }(H=2$ м; $a=0,3-0,5$ м)

\begin{tabular}{|c|c|c|c|c|c|c|c|c|c|}
\hline \multirow{2}{*}{ Параметр } & \multicolumn{3}{|c|}{$W_{t o t}=50 \mathrm{M}^{3}$} & \multicolumn{3}{|c|}{$W_{t o t}=100 \mathrm{M}^{3}$} & \multicolumn{3}{|c|}{$W_{t o t}=500 \mathrm{M}^{3}$} \\
\hline & $a=0,3 \mathrm{M}$ & $a=0,4 \mathrm{M}$ & $a=0,5 \mathrm{M}$ & $a=0,3 \mathrm{M}$ & $a=0,4 \mathrm{M}$ & $a=0,5 \mathrm{M}$ & $a=0,3 \mathrm{M}$ & $a=0,4 \mathrm{M}$ & $a=0,5 \mathrm{M}$ \\
\hline $\begin{array}{l}\text { Коефіцієнт закладання } \\
\text { відкосів бурту } m_{\text {opt }}\end{array}$ & 1,74 & 1,76 & 1,79 & 2,1 & 2,13 & 2,16 & 3,19 & 3,24 & 3,29 \\
\hline Ширина бурту $B_{o p t}, \mathrm{M}$ & 6,960 & 7,040 & 7,160 & 8,400 & 8,520 & 8,640 & 12,76 & 12,96 & 13,16 \\
\hline Довжина бурту $L_{\text {opt }}, \mathrm{M}$ & 4,864 & 4,756 & 4,597 & 9,105 & 8,897 & 8,694 & 34,93 & 34,26 & 33,61 \\
\hline Відносна довжина $L_{o p t} / H$ & 2,432 & 2,378 & 2,298 & 4,552 & 4,449 & 4,347 & 17,47 & 17,13 & 16,80 \\
\hline Ефективний об'єм $W_{e f}, \mathrm{M}^{3}$ & 32,29 & 27,39 & 22,97 & 66,82 & 57,45 & 48,89 & 349,1 & 305,3 & 264,6 \\
\hline $\begin{array}{l}\text { Відносний ефективний } \\
\text { об'єм } W_{\text {max }}^{\prime}\end{array}$ & 0,646 & 0,548 & 0,459 & 0,668 & 0,574 & 0,489 & 0,698 & 0,611 & 0,529 \\
\hline
\end{tabular}

Висновки. Аналіз наявного практичного досвіду підтверджує перспективність застосування технології аеробного біокомпостування осадів стічних вод. Для економічних умов, у яких працюють українські КОС, аеробне біокомпостування виглядає найоптимальнішим способом повної утилізації ОСВ. Перевагою цього методу є отримання органо-мінеральної суміші, що можна ефективно використати для рекультивації територій сміттєзвалищ і техногенно порушених земель.

Розроблено узагальнену математичну модель, що враховує геометричні розміри компостних буртів і товщину зони охолодження, та дає змогу прогнозувати та оптимізувати основні технологічні параметри реалізації процесу аеробного компостування ОСВ. Показано, що без урахування технічних обмежень максимально можливий відносний ефективний об'єм зростає зі збільшенням висоти бурту $H$, коефіцієнта закладання його відкосів $m$ та відносної довжини бурту $L / H$. Для довгих буртів із $L / H \geq 20$ впливом торцевих зон на значення відносного ефективного об'єму можна нехтувати. За сталого значення площі поперечного перерізу довгих буртів максимальні значення відносного ефективного об'єму відповідають коефіцієнту закладання відкосів $m=1$. Розроблена модель дає змогу розв'язати оптимізаційну задачу для фіксованого об'єму компостного бурту за наявності технічних обмежень щодо максимального значення висоти $H$. У практично вагомому діапазоні значень вихідних параметрів $\left(W_{t o t}=50-500 \mathrm{~m}^{3} ; H_{\max }=2 \mathrm{м} ; a\right.$ $=0,3-0,5$ м) максимальний відносний ефективний об'єм відповідає буртам невеликої довжини $L / H<20$ зі значеннями коефіцієнта закладання відкосів $m>1.3$ фізичного погляду такі бурти мають мінімальну площу поверхні розділу з повітрям, що мінімізує об'єм зон охолодження за сталого об'єму і висоти бурту.

\section{Перелік використаних джерел}

Barberio, G., Cutaia, L., \& Librici, V. (2013). Treatment and disposal of sewage sludge: comparative life cycle assessment on Italian case study. Environmental Engineering and Management Journal, 12(11), 7-10.

Białobrzewski, I., Mikš-Krajnik, M., Dach, J., Markowski, M., Czekała, W., \& Głuchowska, K. (2015). Model of the sewage sludgestraw composting process integrating different heat generation capacities of mesophilic and thermophilic microorganisms. Waste Management Journal, 43, 72-83.

Bień, J. D., \& Bień, B. (2015). Zagospodarowanie komunalnych osadów ściekowych metodami termicznymi w obliczu zakazu składowania po 1 stycznia 2016. Inzynieria Ekologiczna, 45, 36-43.

Holub, H. A., \& Pavlenko, S. I. (2016). Modeliuvannia protsesu rukhu kompostu po lopati barabana pid chas rozpushuvannia burtiv. Kompostuvannia, vyrobnytstvo ta ekspluatatsiia silskohospodarskykh mashyn, 46, 20-29. [In Ukrainian].

Horodnii, M. M. (2013). Problemy vykorystannia osadiv stichnykh vod dlia vyrobnytstva dobryv. Ahroekolohiia, radiolohiia, melioratsiia, 9, 45-50. [In Ukrainian].

Pavlenko, S. I., Liashenko, O. O., Lysenko, D. M., \& Kharytonov, V. I. (2011). Analiz i obgruntuvannia tekhnolohichnykh protsesiv kompostuvannia silskohospodarskykh orhanichnykh vidkhodiv tvarynnoho pokhodzhennia. Zbirnyk naukovykh prats Vinnytskoho natsional. ahrarnoho u-tu, 59, 94-104. [In Ukrainian].

Świerczek, L., Cieślik, B. M., \& Konieczka, P. (2018). The potential of raw sewage sludge in construction industry - A review. Journal of Cleaner Production, 200, 342-356.

Volskyi, V. V., Odukha, M. S., Malovanyy, M. S., Zhuk, V. M., Verbovskiy, O. V., \& Popadiuk, I. Y. (2017). Tekhnolohichni aspekty vprovadzhennia kompostuvannia osadiv stichnykh vod v Ukraini. Vodopostachannia ta vodovidvedennia: proektuvannia, budova, ekspluatatsiia, monitorynh: Materialy II Mizhnarodnoi naukovotekhnichnoi konferentsii, Lviv, October 18-20, 2017. (pp. 67-69). [In Ukrainian].

Wong, J. W. C., Selvam, A., \& Awasthi, M. K. (2016). Composting for organic waste management. Sustainable Solid Waste Management. Reston, Virginia: American Society of Civil Engineers, 728.

Zhuk, V. M., Popadiuk, I. Y., \& Verbovskiy, O. V. (2015). Analiz dosvidu anaerobnoho zbrodzhuvannia osadiv stichnykh vod u konteksti yoho zastosuvannia na Lvivskykh kanalizatsiinykh ochysnykh sporudakh. Scientific Bulletin of UNFU, 25(10), 162-165. [In Ukrainian].

В. М. Жук, О. В. Вербовский, И. Ю. Попадюк, И. И. Матлай Национальный университет "Львовская политехника", г. Львов, Украина

\section{ОСНОВНЫЕ ТЕХНОЛОГИЧЕСКИЕ ПАРАМЕТРЫ РЕАЛИЗАЦИИ АЭРОБНОГО} БИОКОМПОСТИРОВАНИЯ ОСАДКОВ СТОЧНЫХ ВОД

Перспективным путем утилизации осадков сточных вод на канализационных очистных сооружениях является их аэробное биокомпостирование с получением органо-минеральной смеси. Представлена обобщенная математическая модель, учитывающая геометрические размеры компостных буртов и толщину зоны охлаждения, и позволяющая прогнозировать и оп- 
тимизировать основные технологические параметры реализации процесса аэробного компостирования осадков. Показано, что без учета технических ограничений максимально достижимый относительный эффективный объем возрастает с увеличением высоты бурта $H$, коэффициента заложения его откосов $m$ и относительной длины бурта $L / H$. Для длинных буртов с $L / H \geq 20$ влиянием торцевых зон на значение относительного эффективного объема можно пренебречь. При постоянном значении площади поперечного сечения длинных буртов максимальные значения относительного эффективного объема соответствуют коэффициенту заложения откосов $m=1$. Разработанная модель дает возможность решать оптимизационные задачи для фиксированного объема компостного бурта при наличии технических ограничений относительно максимального значения высоты $H$. В практически значимом диапазоне значений выходных параметров $\left(W_{t o t}=50-500 \mathrm{~m}^{3} ; H_{\max }=2 \mathrm{~m} ; a=\right.$ 0,3-0,5 м) максимальный относительный эффективный объем соответствует буртам небольшой длины со значениями коэффициента заложения откосов $m>1$. Это объяснено тем, что такие бурты имеют минимальную площадь поверхности раздела с воздухом, за счет чего минимизируется объем зон охлаждения при постоянном объеме и высоте бурта.

Ключевые слова: аэробное биокомпостирование; осадки сточных вод; активная зона; зона охлаждения; относительный эффективный объем; оптимизационная задача.

V. M. Zhuk, O. V. Verbovskiy, I. Yu. Popadiuk, I. I. Matlai Lviv Polytechnic National University, Lviv, Ukraine

\section{THE MAIN TECHNOLOGICAL PARAMETERS OF THE IMPLEMENTATION OF AEROBIC} BIOCOMPOSTING OF SEWAGE SLUDGE

The main method of sewage sludge dewatering and stabilization at Ukrainian wastewater treatment plants (WWTP) still remains their disposal on the sludge sites. Large volumes of sewage sludge generated and accumulated over the decades on Ukrainian WWTP is a serious threat to the environment. The storage of the sewage sludge is forbidden in the EU countries beginning 2016 and the sludge sites can no longer be used for sewage sludge processing. A promising way to utilize sewage sludge at WWTP is the aerobic biocomposting with the production of organic-mineral mixture. The paper presents a generalized mathematical model concerning the geometrical dimensions of the compost heaps and the thickness of the cooling zone, and allowing us to predict and optimize the main technological parameters of the implementation of the process of aerobic composting of sewage sludge. It is shown that without any technical limitations, the maximum achievable relative effective volume increases with an increase in the height of the heap $H$, the slope coefficient $m$ and the relative length of the heap $L / H$. For very long heaps (with $L / H \geq 20$ ) the influence of the end zones on the value of the relative effective volume can be neglected. With a constant value of the cross-sectional area of long heaps, the maximum values of the relative effective volume correspond to the slope coefficient $m=1$. The developed model enables solving optimization problems for a fixed volume of a compost heap when there are strong technical limitations regarding the maximum value of height $H$. In a practically significant range of values of input parameters $\left(W_{t o t}=50-500 \mathrm{~m}^{3} ; H_{\max }=2 \mathrm{~m} ; a=0.3-0.5 \mathrm{~m}\right)$ the maximum relative effective volume corresponds to heaps of small length with values of the slope coefficient $m>1$. This is explained by the fact that such heaps have a minimum free surface with air, thereby minimizing the volume of cooling zones at a constant volume and height of the shoulder.

Keywords: aerobic biocomposting; sewage sludge; active zone; cooling zone; relative effective volume; optimization problem. 